\title{
Design of cooperative update mechanism of national geographic conditions monitoring and basic surveying and mapping
}

\author{
LUO Fujun ${ }^{\mathrm{a}, ~ *}$, ZHAO Yousong ${ }^{\mathrm{a}}$ \\ ${ }^{a}$ National Quality Inspection and Testing Center for Surveying and Mapping Products, LUO Fujun, \\ luofj@sbsm.gov.cn, ZHAOYousong,zhaoys@sbsm.gov.cn \\ * Corresponding author
}

Keywords: National geographic conditions monitoring, Basic Surveying and Mapping, Cooperative Update, Integrated Operation

\begin{abstract}
:
National geographic conditions monitoring and basic surveying and mapping are two important tasks of the surveying and mapping department, and they are similar in production organization and technology realization. In the process of operation, both of them need to carry out internal collection, base map production, field verification and so on. It is operationally feasible to carry out cooperative production of national geographic conditions monitoring and basic surveying and mapping. From the perspective of technical process and method, both of them are carried out by combination internal and field work. Firstly, based on remote sensing images and thematic geographic data, the internal work will perform image interpretation and obtain staged results data. Then, the field verification will be carried out to make judgments and adjustments. Finally, the results of the field verification will be transferred back to the internal work, and the data will be further edited and organized in the internal work to obtain the final data.

Basic surveying and mapping focuses on abstract representation of the real world, but lacks comprehensive integration of information and in-depth knowledge mining. National geographic condition monitoring focuses on the spatial distribution, characteristics and interrelations of natural and human geographical elements on the surface. There are many differences between basic surveying and mapping and national geographic conditions monitoring in the content and index of data collection, data stratification and element attribute. But basic surveying and mapping results are the basic data for national geographic conditions monitoring and national geographic conditions monitoring data is an important update data source for basic surveying and mapping.

On the one hand, part of the geographic information can be updated on the basis of extracting relevant basic geographic information element data and attribute information, On the other hand, timely basic geographic information data can be used as the direct basis for the collection of geographic information.

This paper designs the technical methods and workflow of the cooperative update mechanism based on the relevant technical documents of national geographic conditions monitoring and basic surveying and mapping. It will enable one-time acquisition of data needed for the national geographic conditions
\end{abstract}


monitoring and basic surveying and mapping, "one-time collection, classification and utilization". It will save a lot of time and effort, reduce workload and improve productivity. 